\title{
Конформно интегрируемая электронная компонентная база гибкой печатной электроники для Интернета людей
}

\author{
В. Лучинин, д. т.н. ${ }^{1}$, О. Бохов, к.т.н. ${ }^{2}$, И. Мандрик ${ }^{3}$, В. Старцев ${ }^{3}$, \\ А. Смирнов ${ }^{3}$, П. Афанасьев, к. т.н. ${ }^{2}$, М. Аньчков ${ }^{3}$, А. Пудова ${ }^{3}$, \\ В. Никонова ${ }^{3}$, С. Шевченко, к. т. н. ${ }^{4}$
}

УДК 621.3 | ВАК 05.27 .01

\begin{abstract}
В современном мире приобретают все большую актуальность тенденции, связанные с сохранением и генерацией "человеческого капитала", повышением качества жизни. В рамках развития этих тенденций сформировалось понятие "Интернет людей" (Internet of People - IoP). Оно отражает виртуальную деятельность человека в инфокоммуникационном пространстве по управлению объектами окружающего мира с использованием биометрических данных и биофункциональных показателей для обеспечения персонализированной среды жизнедеятельности человека. В статье рассматриваются комплекс конструкторскотехнологических решений и практическая реализация конформно* интегрируемой электронной компонентной базы гибкой печатной электроники, которые могут эффективно использоваться в системах Интернета людей.
\end{abstract}

$\checkmark$ еловек как объект Интернета людей обладает собственными биологическими идентификационными признаками, ярко выраженными когнитивными функциями, развитой мультисенсорикой и автономным энергосбережением (табл. 1).

Особенности перехода от Интернета вещей к новому поколению Интернета людей:

- биометрическая идентификация личности (биологический адрес);

- контроль местоположения биообъекта и динамики его перемещения;

- анализ поведения и активности индивида;

- мониторинг биомедицинских параметров;

- активные фармакологическое и нефармакологическое воздействия на человека на основании удаленного анализа его биоданных;

- нейрокогнитивноеуправление человеком интегрированными в одежду или размещаемыми на теле

Санкт-Петербургский государственный электротехнический университет "лЭтИ» (СпбгЭТу «ЛЭтИ»), директор ИЦ «ЦМИД" tech@contractmanufacturing.ru.

СПбГэтУ "ЛЭТИ", старший научный сотрудник, заместитель директора ООО «Инжиниринговый центр «Гибкая печатная электроника и фотоника» («ИЦ "ГПЭиФ»).

спбгэтУ «лэтИ», инженер.

СПбгэтУ «ЛЭТИ», доцент.

Конформность - приспособление к окружающим условиям и объектам. искусственными системами для мониторинга физиологического состояния, биомедицинской диагностики, неинвазивной и инвазивной терапии и биозамещения;

- дистанционное управление человеком окружающими и удаленными объектами за счет киберфизического интерфейса, обеспечивающего преобразование и передачу регистрируемых данных индивида в виде движений и жестов, мыслей и эмоций;

- дистанционное формирование без непосредственного участия человека управляющих воздействий на окружающие его объекты на основании виртуальных процедур анализа биоданных и мониторинга среды обитания.

Гибкая печатная электроника и фотоника [1, 2] может рассматриваться как одно из приоритетных направлений при решении научно-практических задач развития нового поколения Интернета людей, учитывая возможность ее конформной интеграции как в объекты органической, так и неорганической природы. Компоненты гибкой печатной электроники конформно пространственно-геометрически и функционально интегрируются в распределенные сенсорно-управляющие и инфокоммуникационные среды [3], обеспечивая высокую конструктивную адаптивность, эргономичность и экономическую эффективность технических решений $[4,5]$.

Целью работы является представление возможной конструктивно-технологической эволюции персонифицированных носимых конформных автономных 
Таблица 1. Современные направления развития технологий Интернета людей

\begin{tabular}{ll} 
Направление & Функции, назначения \\
Биометрическая идентификация & Идентификация личности и позиционирование индивида \\
\hline Биомедицинская сенсорика & Контроль физиологических параметров \\
\hline Биоэлектронное управление & $\begin{array}{l}\text { Трансдермальная лекарственная терапия и нефармакологическая коррекция } \\
\text { состояния }\end{array}$ \\
\hline Биокогнитивное управление & Нейробиокогнитивный информационный и сенсорно-моторный интерфейсы \\
\hline Бионическое замещение & Биомиметика, искусственные органы, биотехноинтерфейсы \\
\hline $\begin{array}{l}\text { Биоинформационная коммуни- } \\
\text { кабельность }\end{array}$ & Персонализированные сетевые информационные системы, кибербезопасность \\
\hline Биоэнергообеспечение & Автономные биоэнергорекуперирующие системы \\
\hline
\end{tabular}

интеллектуальных идентифицирующих, сенсорных, корректирующих и управляющих систем в рамках развития технологий гибкой печатной электроники.

\section{ИНЖЕНЕРИЯ ИНТЕРНЕТА ЛЮДЕЙ}

Базовые направления Интернета людей отражает совокупность следующих конструкторско-технологических решений:

- умная одежда - пассивный субстрат с размещенными функциональными сенсорными, процессорными, энергообеспечивающими и инфокоммуникационными модулями;

- интеллектуальный текстиль - активный гетерогенный субстрат - носитель интегрируемых функциональных свойств:

- искусственная электронная и фотонная кожа эпидермальные и трансэпидермальные мультифункциональные гибридные сенсорно-корректирующие интерактивные платформы;

- биоинтегрируемые импланты - идентификаторы, стимуляторы, корректоры состояния, искусственные органы.

Особенностями индустрии данных изделий являются:

- широкое использование при изготовлении изделий прецизионных аддитивных струйных, корпускулярных и импринт-технологий;

- реализация процессов с применением 2D-и 3D-субстратов различной физико-химической природы;

- развитие конвергентных технологий на основе органо-неорганической и бионеорганической гибридизации

Как отмечалось ранее [3], базисом для создания функциональных компонентов являются преимущественно аддитивные технологии: капельно-струйные, печатно-матричные трафаретные, аэрозольные и так называемые 3D-MID-технологии, основанные на лазерной модификации поверхности субстрата. Основными особенностями данного вида технологий являются:

- гибкость, малая толщина или трехмерность субстратов;

- низкие температуры процессов формирования рисунка;

- достижение высокого пространственного разрешения $[6,7]$ при струйной печати (до 1 мкм) с возможностью отказа от литографических процессов;

- широкая номенклатура базовых функциональных материалов, обеспечивающих формирование металлических, диэлектрических, магнитных, пьезоэлектрических, оптических и люминесцентных композиций.

Технология гибкой печатной электроники и фотоники интегрируется с процессами 2D и 3D прецизионной сборки, в том числе с использованием утоненной бескорпусной элементной базы, что обеспечивает сохранение гибкости и конформности конструкции.

На тонких гибких подложках толщиной от десятков до сотни микрон могут устанавливаться сверхтонкие кристаллы - утоненные чипы интегральных систем, придающие им в совокупности с субстратами функции сенсоров, излучателей, процессоров, памяти. Фактически создается сложное функциональное изделие например, современный интеллектуальный сенсорноинфокоммуникационный гибкий модуль сверхмалой толщины (менее 200 мкм), конформно встраиваемый в любые объекты. Фактически это новый базис «интернета" различного функционального назначения: от контроля окружающей среды до мониторинга биопараметров и органозамещения.

Совокупность вышеуказанных технологических решений определяет ряд предметных индустриальных направлений гибкой печатной электроники для Интернета людей: 
- мультифункциональные сенсорно-исполнительные компоненты, интегрируемые в одежду или размещаемые на теле человека для биомониторинга и коррекции состояния организма;

- микроаналитические диагностические системы типа "лаборатории на чипе" для биомедицинского экспресс-контроля;

- сверхминиатюрные информационно-коммуникационные модули, конформно интегрируемые в одежду или размещенные на теле биообъекта для его быстрой идентификации, высокоточного позиционирования и передачи информации через персонифицированные носимые электронные средства или сторонние локальные терминалы;

- биосенсорные модули, в том числе камуфлируемые, для расширения функциональных возможностей человека, компенсации утраченных функций и когнитивного управления;

- исполнительные миниатюрные конформно интегрируемые модули для бионических систем органозамещения.

\section{СЕНСОРНО-ИНФОРМАЦИОННАЯ ПЛАТФОРМА ГИБКОЙ ПЕЧАТНОЙ ЭЛЕКТРОНИКИ}

В основу формирования интеллектуальной сенсорно-информационной платформы нового поколения, конформно интегрируемой в биотехносферные инженерные разработки, были положены конструкторско-технологические решения, обеспечивающие создание разнообразных по функциональным возможностям сверхтонких изделий на основе совокупностей модулей (табл. 2). Семейство созданных модулей обеспечивает сбор, обработку, накопление и передачу информации, загрузку программного обеспечения и контроль за работой мультифункциональной системы дистанционно со смартфона, включая процесс энергообеспечения

Комплекс работ по тополого-схемотехническому проектированию и технологической реализации функциональных модулей, включая программные средства управления печатным и микросборочным оборудованием, а также программное обеспечение для взаимодействия со всеми подсистемами смартфона, выполнен в Санкт-Петербургском государственном электротехническом университете "лэти» на базе Инжинирингового центра "Гибкая печатная электроника и фотоника".

Выделим лишь совокупность достаточно уникальных технологий, разработанных в СПбГЭТУ «лЭТИ» в процессе конструкторско-технологической практической реализации сверхтонкой конформно интегрируемой сенсорноинформационной платформы нового поколения, созданной на основе технологий гибкой печатной электроники и адаптированных к ней процессов микросборки функциональных модулей:

- декапсуляция кристаллов интегральных микросхем без потери их работоспособности;

- утонение кристаллов-чипов функциональных компонентов до 30-70 мкм с высоким выходом годных без нарушения работоспособности;

- роботизированная стековая сборка кристалловчипов с обеспечением их вертикальной функциональной интеграции;

- технология мультислоевой псевдопланаризации поверхности по периметру утоненного кристалла бескорпусного компонента, размещенного на подложке, с реализацией многоуровневой токоразводки и контактирования с выводами кристалла-чипа методом локальной каплеструйной печати без нарушения сплошности и разрывов шин коммутации;

- технология локального каплеструйного "доращивания" внешних контактных систем кристалла-чипа для обеспечения его монтажа на подложке методом перевернутого кристалла;

- технология высокоточного позицирования при монтаже кристаллов-чипов интегральных микросхем методом перевернутого кристалла с формированием на подложке каплеструйной печатью рельефного диэлектрического слоя определенной топологии для обеспечения комплементарного совмещения (методом вложения) выводов кристалла с контактными системами подложки;

- разработка печатного узла для оборудования высокоразрешающей каплеструйной печати с субмикроннным разрешением металлическими наноструктурированными композициями с использованием стимулирующего электрического поля, обеспечивающего локальный массоперенос [6, 7];

- программные средства проектирования [10], адаптированные к решению тополого-схемотехнических задач разработки гибридных функциональных модулей на основе бескорпусной элементной базы на гибкой тонкой органической подложке;

- программные средства для управления аппаратными модулями роботизированной линии гибкой печатной электроники [11] и кластера гибкой печатной электроники и фотоники в целом (рис. 1), включая реализацию процессов технохимии, комплекса операций 2D-печати и прецизионной 2D- и 3D-микросборки компонентов на гибких и твердых субстратах различной физико-химической природы.

Базовые функциональные узлы (модули), реализованные на полимерном субстрате (125 мкм), представлены в табл. 2.

В качестве унифицированных платформ, технически реализованных с использованием имеющихся 
Таблица 2. Банк функциональных модулей, созданных в СПбГЭТу «ЛЭТИ» на тонком субстрате (125 мкм) на основе технологий гибкой печатной электроники

Базовые элементы и компоненты

Многоуровневая гибкая коммутационная шина - шлейф
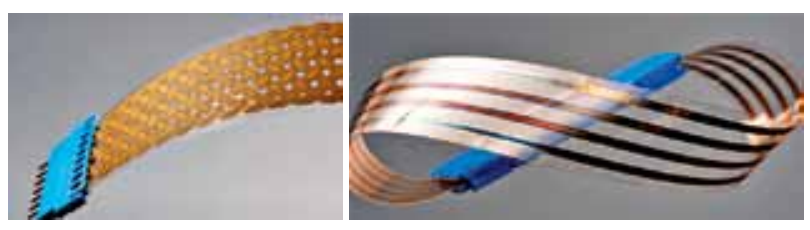

Многоуровневая токоразводка от выводов утоненных кристаллов-чипов процессора и памяти

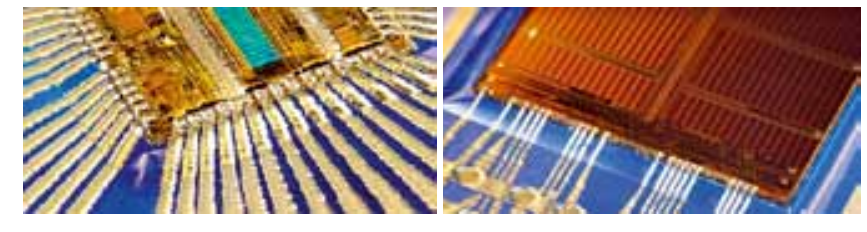

Коммутационное поле для монтажа кристалла по технологии «флип-чип»

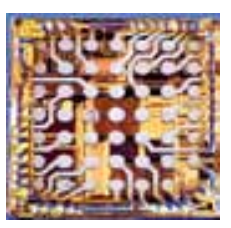

Резисторы [8]

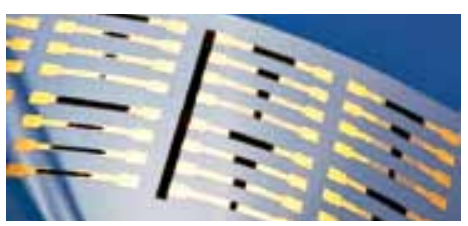

Конденсаторы [8]

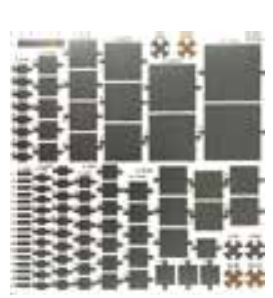

\begin{abstract}
Индуктивности [8]
\end{abstract}

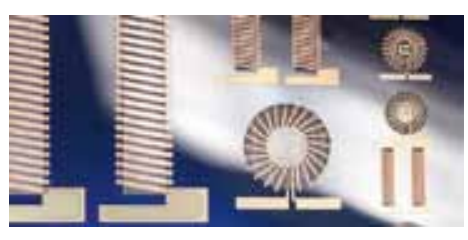

Антенны [9]

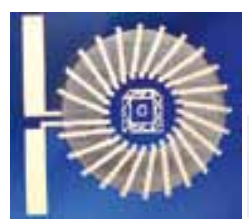

Характеристики и особенности

- Технология каплеструйной печати;

- многослойная композиция: диэлектрик (субстрат) металл - диэлектрик;

- материал токопроводящих шин: наносеребро;

- материал изолирующего диэлектрического слоя: полиимид

- Технология каплеструйной печати;

- технология утоненного кристалла;

- технология мультислоевой диэлектрической псевдопланаризации поверхности по периметру кристалла;

- планализатор: полиимид;

- межслойная изоляция: полиимид;

- материал токоразводки: наносеребро;

- ширина проводника: от 40 мкм;

- толщина проводника: от 0,5 до 10 мкм

- Технология каплеструйной печати;

- печатная технология диэлектрических окон;

- печатная технология "доращивания" контактных систем;

- материал контактных систем: наносеребро;

- материал изоляции: полиимид

- Технология каплеструйной печати;

- резистивный материал: наноуглерод;

- контактные системы: наносеребро;

- номиналы: от 50 Ом до 10 МОм

- Технология каплеструйной печати;

- многослойная композиция: металл - диэлектрик металл;

- диэлектрик: полиимид;

- металлические обкладки: наносеребро;

- толщина: от 30 мкм;

- номиналы: от 20 пФ до 2 нФ

- Технология каплеструйной печати;

- многослойная композиция (катушка): металл магнитный материал (сердечник) - металл;

- материал проводников: наносеребро;

- материал сердечника: наножелезо;

- толщина: от 30 мкм;

- номиналы: от 10 нГн до 1 мГн

- Технология каплеструйной печати;

- материал антенны: наносеребро;

- тип антенны: диполь, патч, мультивибратор;

- частота: от 100 МГЦ до 10 ГГц, характеристики зависят от материала подложки 
Таблица 2. Продолжение

Базовые элементы и компоненты

Модуль памяти

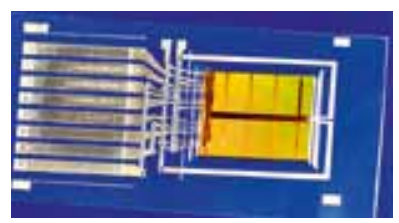

Блок микроконтроллера

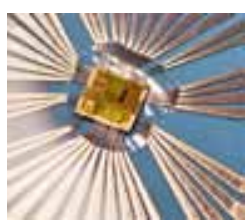

Модуль NFC-интерфейса
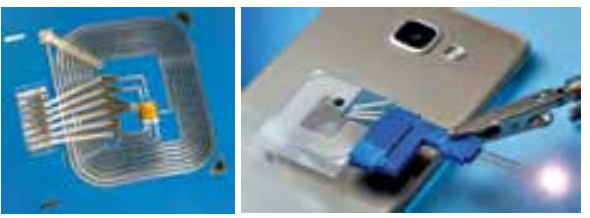

Модуль UHF-интерфейса

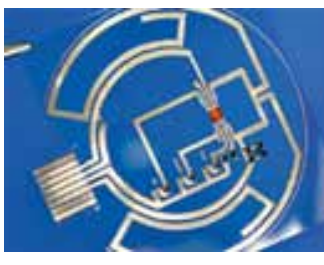

Модуль Bluetooth-интерфейса

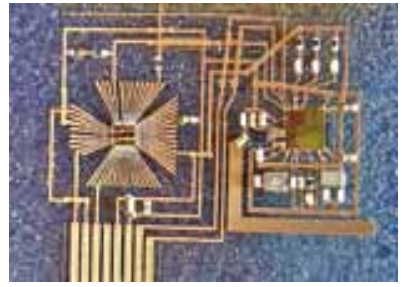

Модуль беспроводной

зарядки

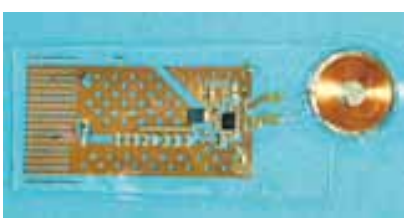

Блок стабилизации напряжения питания

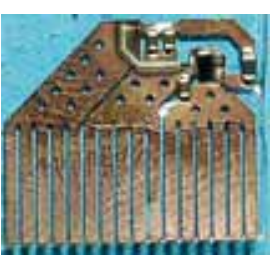

Характеристики и особенности

- Технология каплеструйной печати контактных систем;

- технология утоненного кристалла памяти;

- утонение чипа: от 760 до 75 мкм

- Технология каплеструйной печати контактных систем;

- технология утоненного кристалла микроконтроллера;

- утонение чипа: от 330 до 30 мкм

- Технология каплеструйной печати;

- технология многоуровневой коммутации;

- материал коммутации: наносеребро;

- материал изоляции: полиимид;

- технология утоненного кристалла NFC;

- печатная антенна;

- рабочая частота: 13,56 МГц

- Технология каплеструйной печати;

- технология многоуровневой коммутации;

- материал коммутации: наносеребро;

- материал изоляции: полиимид;

- технология утоненного кристалла UHF;

- навесные низкопрофильные компоненты;

- печатная антенна;

- рабочая частота: от 865 до 965 МГц

- Технология каплеструйной печати;

- технология многоуровневой коммутации;

- материал коммутации: наносеребро;

- материал изоляции: полиимид;

- технология утоненного Bluetooth-кристалла;

- технология утоненного микроконтроллера;

- навесные низкопрофильные компоненты;

- печатная антенна;

- толщина модуля: 550 мкм

- Технология каплеструйной печати;

- технология многоуровневой коммутации;

- материал коммутации: наносеребро;

- материал изоляции: полиимид;

- навесные низкопрофильные компоненты;

- толщина модуля: не более 700 мкм

- Технология каплеструйной печати;

- технология многоуровневой коммутации;

- материал коммутации: наносеребро;

- материал изоляции: полиимид;

- навесные низкопрофильные компоненты;

- толщина модуля: 650 мкм 
Таблица 2. Продолжение

Базовые элементы и компоненты

Сенсорная платформа с микроконтроллером

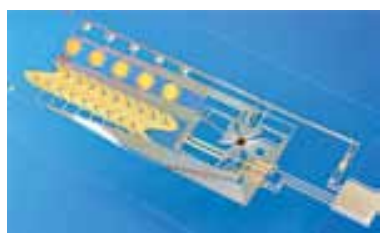

Интеллектуальная сенсорно-информационная платформа

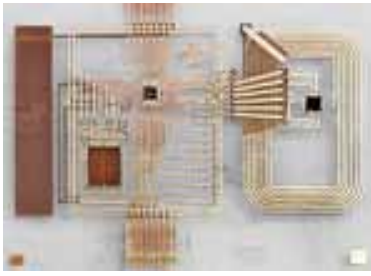

Характеристики и особенности

- Технология каплеструйной печати;

- технология многоуровневой коммутации;

- материал коммутации: наносеребро;

- материал изоляции: полиимид;

- технология утоненного кристалла микроконтроллера;

- навесные низкопрофильные компоненты;

- сенсорная панель

- Технология каплеструйной печати;

- технология многоуровневой коммутации;

- материал коммутации: наносеребро;

- материал изоляции: полиимид;

- технология утоненных кристаллов: процессор, память, NFC-радиоинтерфейс;

- печатная антенна;

- сенсорная панель в Инжиниринговом центре «Гибкая печатная электроника и фотоника" [12] печатных и микросборочных технологий, были определены два интеллектуальных сенсорных модуля, отличающихся видом инфокоммуникационного канала (электрический или радиотехнический) и возможностью накопления информации в специализированной памяти. $\because \because$

Представленные приоритетные отечественные конструкторско-технологические решения, реализованные в Санкт-Петербургском государственном электротехническом университете "ЛЭТИ" в области гибкой печатной электроники, являются наиболее прогрессивными для формирования персонифицированной биомедицинской

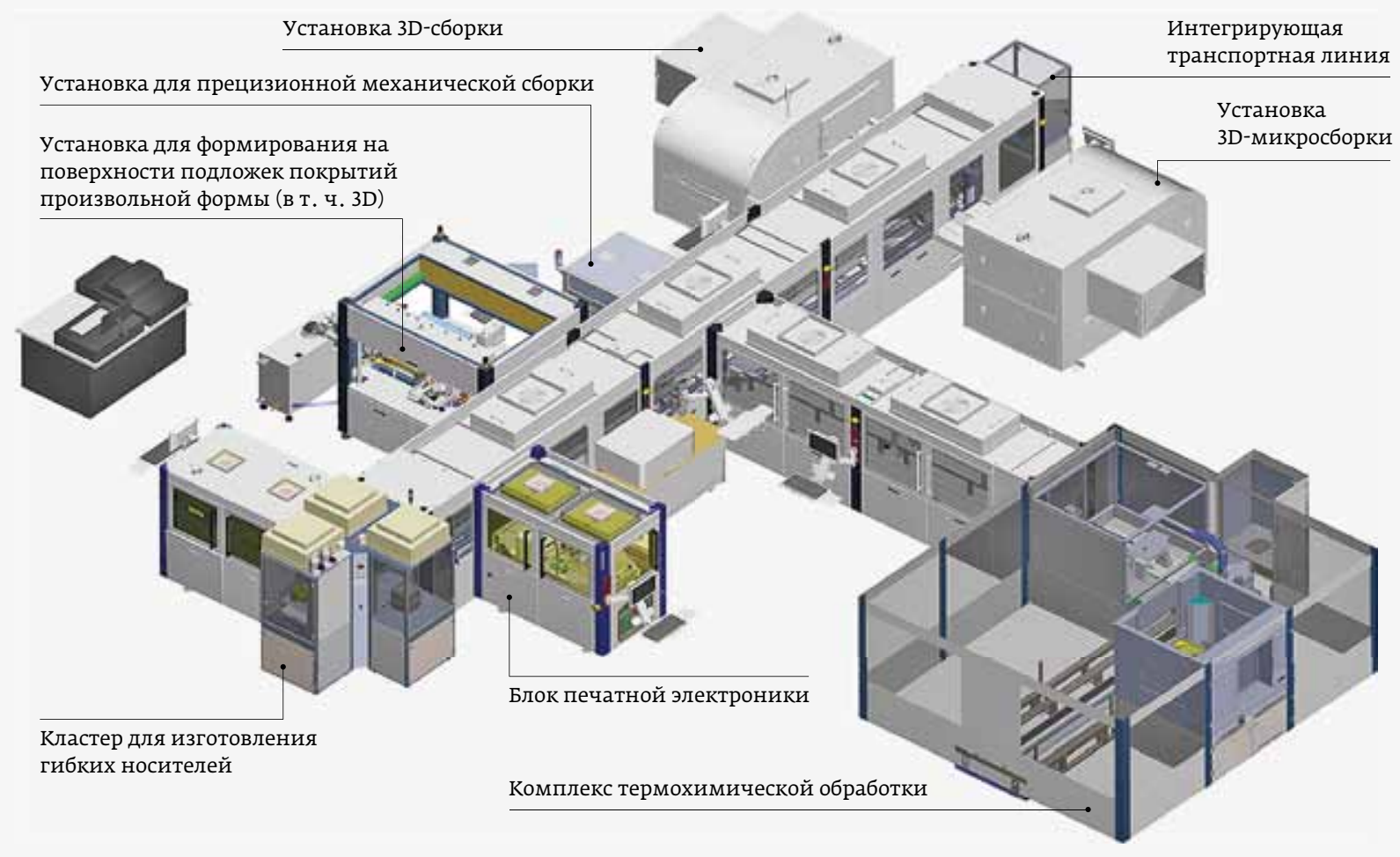

Рис. 1. Кластер гибкой печатной электроники и фотоники, разработанный в СПбГЭТУ «ЛЭТИ" 
техносферы. Интегрируемые в одежду эпидермальные и имплантируемые биоинтегрируемые персонифицированные интеллектуальные сенсорные, процессорные, энерго- и инфообеспечивающие микро- и наносистемные платформы на гибких конформных носителях являются базисом Интернета людей, определяющим качество жизни человека и, безусловно, неисчерпаемый рынок наукоемкой высокоинтеллектуальной и креативной продукции [13].

По нашему мнению, наибольший интерес применительно к использованию гибких печатных элементов представляют персонифицированные конформно интегрируемые в одежду интеллектуальные сенсорные и корректирующие (фармакологические и нефармокологические) устройства для контроля биомедицинских показателей, анализа активности индивида, корректировки поведения и физиологического состояния. Для интеграции пригодны любые элементы: одежда, обувь и даже кожа человека.

Одежда и эпидермальные системы представляют интерес в первую очередь для людей пожилого возраста, поскольку они позволяют постоянно мониторить не только такие параметры, как пульс, артериальное давление, содержание сахара в крови, но и двигательную активность человека, положение его тела, прием лекарственных препаратов, а также дистанционно управлять техническими устройствами в условиях нарушения органов движения. Фактически устройства гибкой печатной электроники это конформная интеллектуальная платформа нового поколения для следующей генерации Интернета людей.

В настоящее время "умная» одежда стоит достаточно дорого, однако сама технология гибкой печатной электроники обеспечивает возможность массового тиражирования функциональных модулей. Созданные в СПбГЭТу «лЭТИ» отдельные модули уже сейчас можно дистанционно интегрировать с "умным" телефоном, расширив функциональные возможности человека.

В случае технологической конформной интеграции систем гибкой печатной электроники в одежду ее стоимость должна быть даже ниже, чем при стандартном размещении на человеке в виде совокупности современных электронных устройств с системами энергосбережения.

Известное высказывание: "Доброта - это то, что слышит глухой и видит слепой»- применительно к Интернету людей может быть представлено как технология социально-ориентированной биотехносферной интеллектуальной "доброты» ноосферы, то есть современной сферы разума и технологических возможностей человека.

\section{ЛИТЕРАТУРА}

1. Tsuyoshi Sakitani, Takao Someya. Ambient Electronics // Japanese Journal of Applied Physics. 2012. V. 51,

P. 100001-1-100001-13.
2. Лучинин В.в. Мультидисциплинарные технологии Гибкая электроника и фотоника // Нано-и микросистемная техника. 2013. № 12 (161). С. 2-6.

3. Лучинин В.В., Бохов О.С., Афанасьев П. В., Мандрик И. В., Старцев В.А., Смирнов А. В., Никонова В.А. Гибкая печатная конформная электроника. Отечественные компетенции и электронные компоненты // НАНОИНДУСТРИЯ. 2019. Т. 12. № 6(92). С. 342-350.

4. Ильин С. Ю., Лучинин В. В. Эпидермальные биоинтегрируемые персонифицированные интеллектуальные сенсорные и корректирующие микро- и наносистемы // Биотехносфера. 2017. № 3 (51). С. 2-14.

5. Ильин С. Ю., Лучинин М. В. Интеллектуальная искусственная кожа - эпидермальный мониторинг и коррекция биообъектов // Нано- и микросистемная техника. 2017. Т. 19. № 8. С. 499-507.

6. Бохов О.С., Афанасьев П. В. Электрогидродинамический способ печати наноразмерных 2D- и 3D-структур // Нано- и микросистемная техника. 2017. Т. 19. № 8. С. 475-478.

7. Bochov O., Afanasev P., Grooten M., Henk van Broekhuyzen, Startsev V., Mandrik I., Nikonova V., Smirnov A. Super inkjet technology machine development for additive 3D Manufacturing // International Scientific Journal "Industry 4.0". 2019. Р. 175-178

8. Афанасьев П. В., Бохов О.С., Мандрик И. В., Старцев В.А. Каплеструйная технология гибкой печатной электроники для изготовления пассивных компонентов // Нано- и микросистемная техника. 2017. Т. 19 № 8. С. 465-468.

9. Топталов С. И., Устинов Е. М., Афанасьев П. В., Бохов О.С., Мандрик И. В., Старцев В.А. Создание антенных печатных модулей каплеструйной технологией // Нано- и микросистемная техника. 2017. Т. 19 № 8. С. 470-473.

10. Бороденков Н. И., Бохов О.С., Смирнов А. В., Шилков В. М. Разработка программных средств для проектирования и создания устройств гибкой печатной электроники // Нано- и микросистемная техника. 2017. Т. 19. № 8. С. 459-462.

11. Афанасьев П. В., Бохов О.С., Лучинин В.В. Научно-технологический комплекс экспресспрототипирования изделий гибкой электроники и фоТоникИ // НАНОИНДУСТРИЯ. 2013. № 6(44). С. 94-104.

12. Лучинин В.В. Российский пилотный проект инжинирингового центра "Гибкая печатная электроника и фотоника" // Нано-и микросистемная техника. 2017 Т. 19. № 8. С. 451-455

13. Лучинин В.В. Индустрия микро- и наносистем: от импортозамещения к технологическому суверенитету // НАНОИНДУСТРИЯ. 2018. Т. 11. № 6(85). С. 450-461. 
КОМПЛЕКС

ЭЛЕКТРОГИДРОДИНАМИЧЕСКОЙ СТРУЙНОЙ

МИКРО. И НАНОРАЗМЕРНОЙ 2D И 3D ПЕЧАТИ

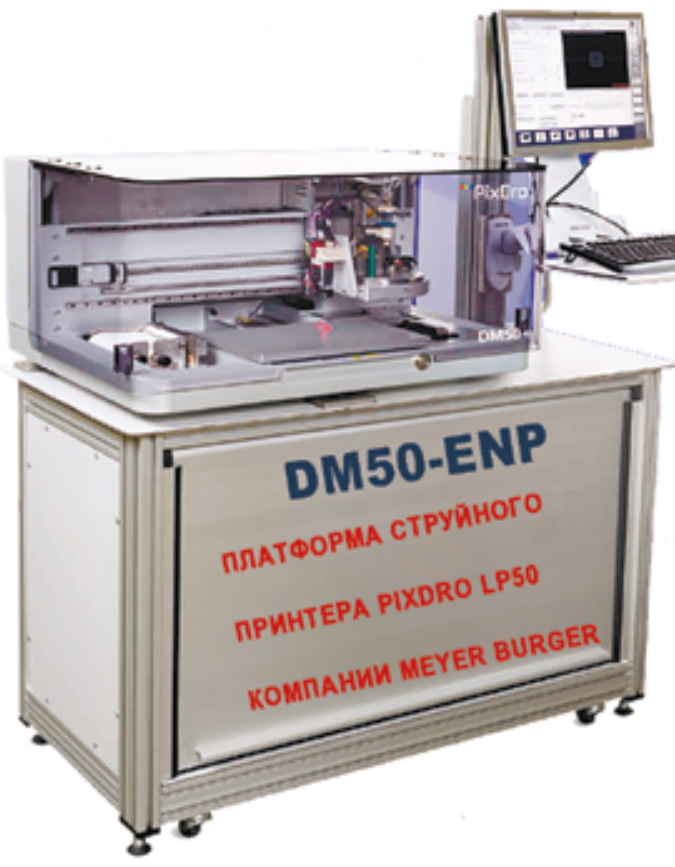

Совместная разра6отка DoMicro

и 000 Инжиниринговый центр

"Гибкая печатная электроника и фотоника"

Микро- и наноразмерное формооборазование

в сильном электрическом поле

ГИБКАЯ ПЕЧАТНАЯ

ЭЛЕКТРОНИКА И ФОТОНИКА

- Бесшаблонные печатные технологии

- Субмикронное пространственное разрешение

- Многообразие печатных функциональных материалов

- Универсальная (базовая) платформа капельно-струйных 2D принтеров

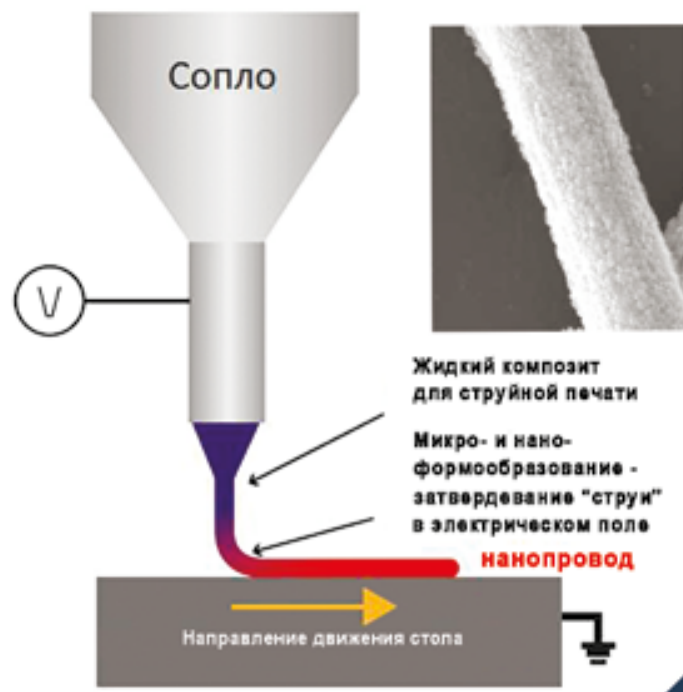

ПРОИЗВОДСТВО 2D И 3DИНТЕГРИРОВАННЫХ МИКРОСИСТЕМ

- ИНTЕРНЕТ ВЕЩЕЙ

- УМНАЯ ОДЕЖДА

- ЛАБОРАТОРИИ НА ЧИПЕ

- RFID METKИ 